\title{
Measurement and Evaluation of the Normal Range of Maximal Mouth Opening and Its Correlation with Age, Body Height, Weight, and Gender in the Young Indian Population
}

\author{
${ }^{1}$ Arun Kumar, ${ }^{2}$ Anita Hooda, ${ }^{3}$ Joginder Gulia, ${ }^{4}$ Deepali Agarwal, ${ }^{5}$ Vijay Kumar
}

\begin{abstract}
Aim: To measure and evaluate the normal range of maximal mouth opening (MMO) in young children aged 3 to 12 years from Indian population and to examine the possible influence of age, gender, height, and body weight on MMO.

Materials and methods: The assessment of MMO is accomplished with a modified Vernier caliper by measuring the distance between the incisal edge of upper and lower incisor during $\mathrm{MMO}$ up to the painless limit. Participants of the study were healthy children selected among regular students from local schools. Age, gender, height, and body weight of each child were also recorded at the same time.
\end{abstract}

Results: The results of the present study revealed that $\mathrm{MMO}$ in Indian children was 41.61, 44.9, and $46.81 \mathrm{~mm}$ for boys and $40.09,44.22$, and $46.2 \mathrm{~mm}$ for girls at age of 3,4 , and 5 years respectively. In mixed dentition, the MMO in Indian children was $46.04,48.53$, and $52.38 \mathrm{~mm}$ for boys and $45.95,47.27$, and $52.05 \mathrm{~mm}$ for girls at age groups of 6 to 8,8 to 10 , and 10 to 12 years respectively. Further significant associations were noted between age, height, body weight, and MMO. However, no gender difference was observed.

Conclusion: A definite relationship exists between $\mathrm{MMO}$, age, height, and body weight in Indian children with primary dentition as well as in mixed dentition.

Keywords: Age, Body height, Body weight, Children, Gender, Mouth.

How to cite this article: Kumar A, Hooda A, Gulia J, Agarwal D, Kumar V. Measurement and Evaluation of the Normal Range

\footnotetext{
${ }^{1}$ Assistant Professor, ${ }^{2}$ Senior Professor and Head, ${ }^{3}$ Professor ${ }^{4}$ Postgraduate Student, ${ }^{5}$ Senior Resident

${ }^{1}$ Department of Pedodontics and Preventive Dentistry, Post Graduate Institute of Dental Sciences, Rohtak, Haryana, India

${ }^{2}$ Department of Oral Anatomy, Post Graduate Institute of Dental Sciences, Rohtak, Haryana, India

${ }^{3}$ Department of ENT, Pt. Bhagwat Dayal Sharma Post Graduate Institute of Medical Sciences, Rohtak, Haryana, India

${ }^{4}$ Department of Public Health Dentistry, Post Graduate Institute of Dental Sciences, Rohtak, Haryana, India

${ }^{5}$ Department of Oral and Maxillofacial Surgery, Post Graduate Institute of Dental Sciences, Rohtak, Haryana, India

Corresponding Author: Arun Kumar, Assistant Professor Department of Pedodontics and Preventive Dentistry, Post Graduate Institute of Dental Sciences, Rohtak, Haryana, India Phone: +911262280192, e-mail: drarun922@gmail.com
}

of Maximal Mouth Opening and Its Correlation with Age, Body Height, Weight, and Gender in the Young Indian Population. J Oral Health Comm Dent 2018;12(1):14-19.

Source of support: Nil

Conflict of interest: None

\section{INTRODUCTION}

Maximum mouth opening is a significant diagnostic criteria for preliminary evaluation of stomatognathic system especially for those with temporomandibular problems. ${ }^{1}$ The various types of odontogenic infections, oral malignancies, temporomandibular disorders (injuries, ankylosis), mandibular or midface fractures, myopathies, such as resulting from maxilla-mandibular immobilization and trauma can lead to reduced mouth opening. ${ }^{2}$ Furthermore, all pediatric dentists dealing with the oral cavity are faced with varying degrees of difficulty when $\mathrm{MMO}$ is limited.

In spite of heavy significance relating $\mathrm{MMO}$, limited studies have been reported on this subject especially in pediatric population. Pioneer studies regarding mouth opening in children are credited to Nevakari, ${ }^{3}$ Sheppard and Sheppard, ${ }^{4}$ Ingervall, ${ }^{5}$ and Agerberg ${ }^{6}$ but with smaller sample size. As yet, there is no reference for clinicians to determine whether a patient has limited mouth opening capacity, as it is so dependent on other particular physiological characteristics. It is therefore necessary to investigate the correlation between $\mathrm{MMO}$ and any related physiological indicators including age, gender, body height, and body weight in young Indian population.

Few studies had tried to establish a reference of mouth opening in Indian norms especially in young children. ${ }^{3,4}$ Furthermore, the relationship between MMO with age, gender, body height, and body weight is significant but is yet unexplored much in children for comparison. Therefore, the aim of the present study was to measure the normal range on $\mathrm{MMO}$ in young Indian population and to examine the possible relationship between age, gender, body height, and body weight with MMO.

\section{MATERIALS AND METHODS}

The study consisted of 1,383 subjects from different schools (17 schools) in the city of Rohtak, Haryana, India. 
Total 745 boys and 638 girls between the ages of 3 and 12 years (mean age $7.07+0.05$ ) were included in the study.

The patient history was taken and a questionnaire filled for each patient. This was administered at the time of clinical oral examination. The pretested, structured questionnaire consisted of demographic information on each child. The information collected included the age, gender, past history of any trauma, pain or clicking sound at rest or during jaw movements, and head and neck disorders. The child was also being asked to provide information on other types of conditions, such as any systemic diseases, neurological disorders, or craniofacial deformities that would affect the ability to open its mouth. The clinical examination consisted of a general dental examination of inspecting the preuricular area for any swelling, erythema, or tenderness. Palpation directly over the joint when the patient opened and closed the mandible was done. The extent of the mandibular condylar movement and temporomandibular joint auscultation was also done at the same time. The masticatory and cervical muscles were also palpated. Deviation of the mandible during the opening was also observed.

The inclusion criteria were

- No history of jaw, head, and face trauma

- No history of pain in the jaw, face, and neck, either at rest or during function

- No history of severe bruxism

- No facial and dental abnormalities

- No history of temporomandibular joint sounds

- No dental prosthesis on the anterior teeth The exclusion criteria were

- Subjects with severe orthodontic problems (anterior crossbite)

- Neurologic disorders

- Craniofacial deformities

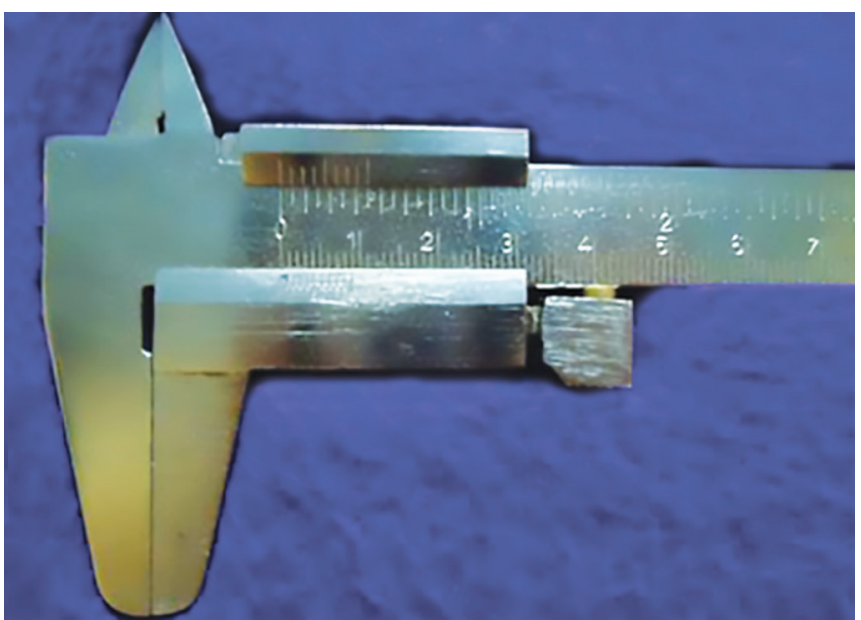

Fig. 1: Vernier caliper (original form) comprising two jaws, larger and smaller, and two scales, Vernier (sliding) scale and main scale
- Systemic diseases, such as juvenile rheumatoid arthritis

- Neck pain

- Any condition that have been reported to create limited mouth opening.

\section{Procedure}

After obtaining informed consent from the respective school authorities, a clinical examination was performed. The MMO was measured by asking each of the subjects to open their mouths as wide as possible, while the examiner measured the maximum distance from the incisal edge of the maxillary central incisor to incisal edge of mandibular central incisor at the midline. For each subject, three readings were recorded in millimeters and the mean value was considered. The MMO measurements were taken using a modified Vernier caliper while the subjects rested their heads against a firm wall surface in an upright position (Fig. 1). The body weight was recorded in kilograms using a weighing balance (equinox) (Fig. 2). The height was measured, without shoes, in centimeters, using a metric scale. All measurements were performed by a single examiner to avoid intraexaminer variability. The measurements of MMO were compared in children of different age groups. Similarly, a correlation between the MMO and body weight and height was also observed.

\section{Study Protocol}

The study was basically conducted in two stages. The first stage encompassed primary dentition with children of age ranging from 3 to 5 years. The children were subdivided in 3,4 , and 5 year age groups. The second stages include children in mixed dentition with age range of 6 to 12 years and therefore were subgrouped as 6 to 8 years, 8 to 10 years, and 10 to 12 years in mixed dentition group.

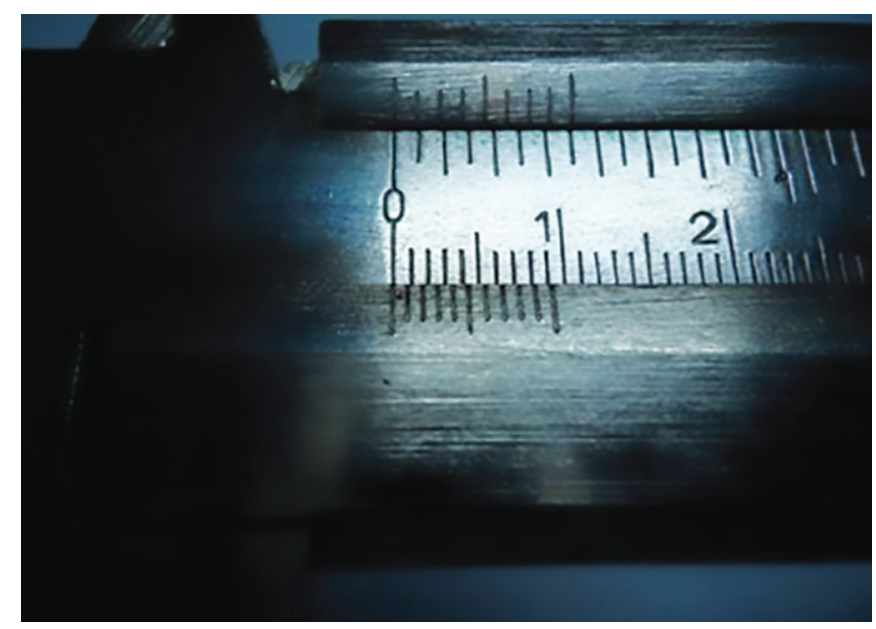

Fig. 2: Sliding (Vernier) and main scale readings 


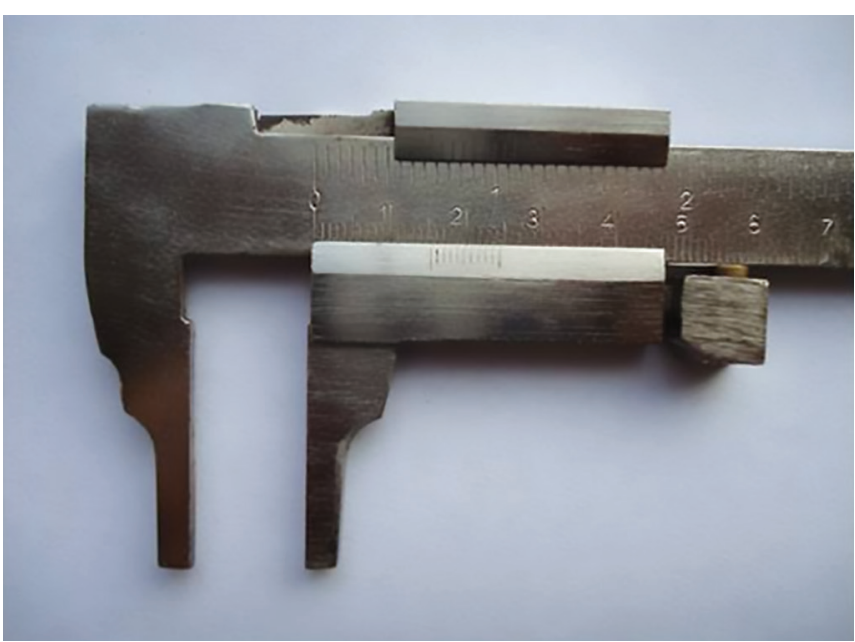

Fig. 3: Modified Vernier caliper (smaller jaw is removed; outer edges of larger jaw are straightened). Distance between two outer straight edges of larger jaw is $9 \mathrm{~mm}$ when zero reading of Vernier scale and main scale coincides. Final readings taken

The children were randomly allocated in groups and subgrouped based on age:

- Group I: Children with primary dentition.

- Subgroup I: children of age 3 years

- Subgroup II: children of age 4 years

- Subgroup III: children of age 5 years.

- Group II: Children with mixed dentition

- Subgroup I: children of age 6 to 8 years

- Subgroup II: children of age 8 to 10 years

- Subgroup III: children of age 10 to 12 years.

The MMO, body weight, and height were recorded in all three groups. The MMO was measured in millimeters, the body weight in kilograms, and body height in centimeters. Measurements of MMO were correlated with body weight and height of children in different age groups as well as in different subgroups.

\section{Statistical Methods}

The study results were analyzed by using the Statistical Package for the Social Sciences (version 20; Chicago, Illinois, USA). Mean and standard error of mean (SEM) were calculated for MMO. Student's t-test and chi-square test were used; $p$-values $\leq 0.05$ were considered as significant. The Shapio-Wilk test was done to test the normality of the data and to determine whether to accept or reject the null hypothesis. The null hypothesis was accepted (significance value of the Shapio-Wilk test was $>0.05$ ). This further suggested that the study data were from a normally distributed population.

\section{Vernier Caliper and Its Modification}

A Vernier caliper is a precise instrument for measuring linear dimension (length) of any object to an accuracy

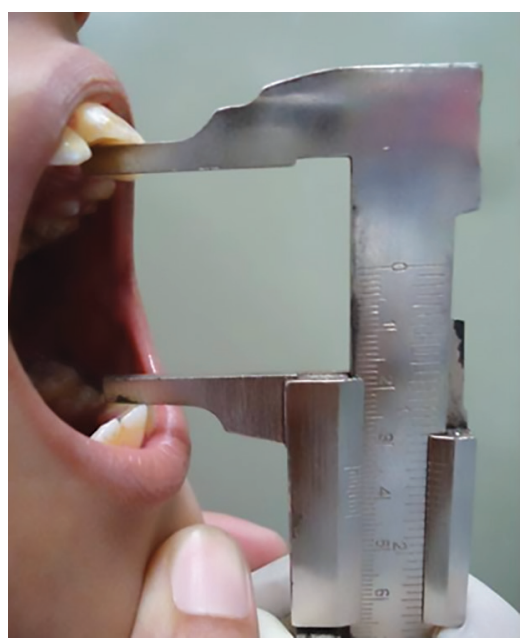

Fig. 4: Method for measuring MMO in children using a modified Vernier caliper method

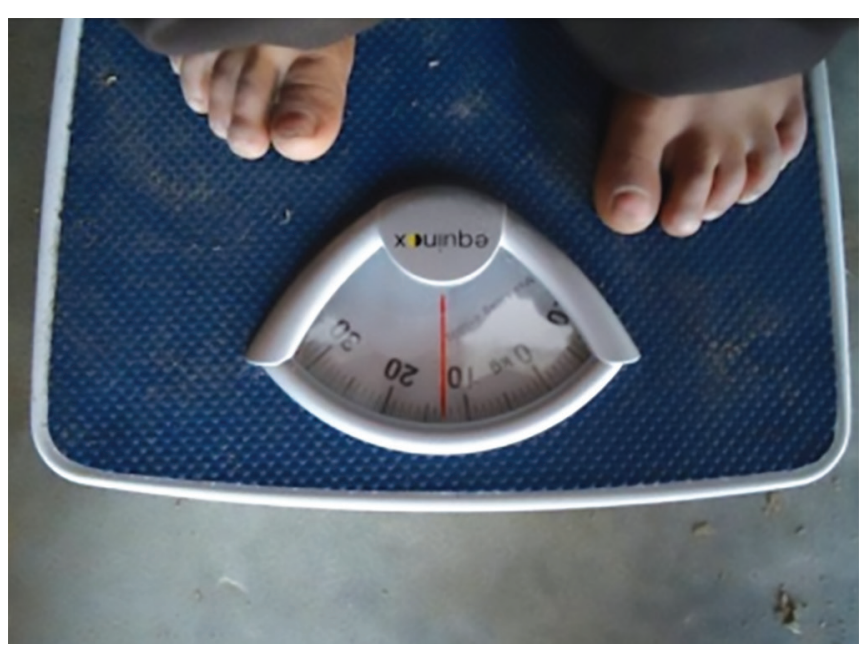

Fig. 5: Method used for measuring the weight of a child

of a tenth of a millimeter or better. It comprises of two jaws, one for measuring outer dimensions (larger jaw) and other for measuring inner dimension (smaller jaw), which are attached to a fixed scale and a sliding (Vernier) scale (Figs 3 and 4). For the present study, Vernier caliper has been modified:

- Jaw used for measuring inner dimension has been removed by machine grinding (Fig. 5).

- Jaw used for measuring outer dimension has been modified in such a way that it can be used for measuring both inner and outer dimension. This is achieved by grinding the outer edges of the larger jaw to make them straight, engaging the inner edges of an object (e.g., interincisal distance) to measure its dimension. The distance between the two outer straight edges of larger jaws is $9 \mathrm{~mm}$ when zero reading of Vernier scale and main scale coincides (Fig. 5).

In the course of modifying the Vernier caliper, a new formula has been derived for measuring the inner 
dimension, using larger arm that is being modified for the purpose. Final readings were taken after adding $9 \mathrm{~mm}$ to the original reading (Fig. 5).

Final reading $=$ Original reading $+9 \mathrm{~mm}$

This is a pioneer method used for measuring MMO in children. The method is safe and simple to execute, reproducible, reliable even in small children, does not affect sensitivity of caliper, and is easy to calculate final reading by adding simple numerical value to original measurement. Further, modified caliper is much lighter in weight, is compact, easy to manipulate, and less fearful particularly to children.

\section{RESULTS}

\section{Group I}

Maximum mouth opening was measured in boys and girls aged between 3 and 5 years (Table 1). The estimated average MMO measured for boys and girls at the age of 3 years was $41.61 \pm 0.32$ and $40.09 \pm 0.34 \mathrm{~mm}$ respectively. The estimated average MMO measured for boys and girls at the age of 4 years was $44.98 \pm 0.38$ and 44.22 $\pm 0.42 \mathrm{~mm}$ respectively. The estimated average $\mathrm{MMO}$ measured for boys and girls at the age of 5 years was $46.81 \pm 0.35$ and $46.22 \pm 0.36 \mathrm{~mm}$ respectively. There is a gradual increase in MMO with age, i.e., from 3 to 5 years. Statistically significant difference was not observed in MMO between boys and girls at various age groups. However, MMO was found to be significantly different when compared between 3 and 5 years (Table 1 ). As shown in Table 1, there was a gradual increase in height of both boys and girls with age. Maximum mouth opening was also found to increase with age. Therefore, a definitive relationship was found between $\mathrm{MMO}$ and height. There was a gradual increase in weight of both boys and girls with age. Maximum mouth opening was also found to increase with weight. Therefore, a definitive relation was also found between $\mathrm{MMO}$ and weight. Results are shown in Table 1.

\section{Group II}

Maximum mouth opening was measured in boys and girls aged between 6 and 12 years (Table 2). The estimated average MMO measured for boys and girls at the age of 6 to 8 years was $46.04 \pm 0.39$ and $45.95 \pm 0.37 \mathrm{~mm}$ respectively. The estimated average $\mathrm{MMO}$ measured for boys and girls at the age of 8 to 10 years was 48.53 \pm 0.31 and $47.27 \pm 0.28 \mathrm{~mm}$ respectively. The estimated average MMO measured for boys and girls at the age of 10 to 12 years was $52.38 \pm 0.36$ and $52.05 \pm 0.35 \mathrm{~mm}$ respectively. There is a gradual increase in $\mathrm{MMO}$ with age that was found to be statistically significant when compared between 6 and 12 years. However, no statistically significant difference was found in MMO between boys and girls at various age groups (Table 2). As shown in Table 1, there was a gradual increase in height of both boys and girls with age. Maximum mouth opening was also found to increase with age. When compared statistically, a significant difference was observed between MMO and height of children at different age groups. There was a gradual increase in weight of both boys and girls with age. Maximum mouth opening was also found to increase with weight. A statistically significant difference was found between $\mathrm{MMO}$ and weight at different ages. Results are shown in Table 2.

Table 1: Maximum mouth opening $(\mathrm{mm})$, height $(\mathrm{cm})$, and body weight $(\mathrm{kg})$ in boys and girls of age 3 to 5 years

\begin{tabular}{lllll}
\hline Age (years) & Gender & MMO $(\mathrm{mm})$ & Height $(\mathrm{cm})$ & Weight $(\mathrm{kg})$ \\
\hline $3(\mathrm{n}=177)$ & Boys $(\mathrm{n}=112)$ & $41.61 \pm 0.32$ & $105.74 \pm 0.75$ & $15.96 \pm 0.28$ \\
& Girls $(\mathrm{n}=65)$ & $40.09 \pm 0.34$ & $104.20 \pm 1.16$ & $14.47 \pm 0.33$ \\
$4(\mathrm{n}=169)$ & Boys $(\mathrm{n}=90)$ & $44.98 \pm 0.38^{*}$ & $112.46 \pm 0.80^{*}$ & $19.09 \pm 0.31^{*}$ \\
& Girls $(\mathrm{n}=79)$ & $44.22 \pm 0.42^{*}$ & $109.87 \pm 0.88^{*}$ & $17.24 \pm 0.26^{*}$ \\
$5(\mathrm{n}=181)$ & Boys $(\mathrm{n}=86)$ & $46.81 \pm 0.35^{*}$ & $114.00 \pm 0.81^{*}$ & $19.71 \pm 0.36^{*}$ \\
& Girls $(\mathrm{n}=95)$ & $46.22 \pm 0.36^{*}$ & $114.87 \pm 0.93^{*}$ & $18.86 \pm 0.35^{*}$ \\
\hline
\end{tabular}

${ }^{*} p<0.01$ when compared with mean readings of 3 years; Data are presented as mean \pm SEM

Table 2: Maximum mouth opening $(\mathrm{mm})$, height $(\mathrm{cm})$, and body weight $(\mathrm{kg})$ in boys and girls of age 6 to 12 years

\begin{tabular}{lllll}
\hline Age $($ years $)$ & Gender & $M M O(\mathrm{~mm})$ & Height $(\mathrm{cm})$ & Weight $(\mathrm{kg})$ \\
\hline $6-8(\mathrm{n}=276)$ & Boys $(\mathrm{n}=149)$ & $46.04 \pm 0.39$ & $125.89 \pm 0.55^{\pi}$ & $21.61 \pm 0.21^{@}$ \\
& Girls $^{\mu}(\mathrm{n}=127)$ & $45.95 \pm 0.37$ & $123.53 \pm 0.71$ & $21.46 \pm 0.28^{\circledR}$ \\
$8-10(\mathrm{n}=296)$ & Boys $(\mathrm{n}=157)$ & $48.53 \pm 0.31^{*}$ & $136.72 \pm 0.58^{*, \pi}$ & $30.90 \pm 0.48^{*, @}$ \\
& Girls $(\mathrm{n}=139)$ & $47.27 \pm 0.28^{*}$ & $134.53 \pm 0.50^{\pi}$ & $29.46 \pm 0.39^{*}$ \\
$10-12(\mathrm{n}=284)$ & Boys $(\mathrm{n}=151)$ & $52.38 \pm 0.36^{*}$ & $140.80 \pm 0.70^{*, \pi}$ & $32.84 \pm 0.59^{*, @}$ \\
& Girls $^{\mu}(\mathrm{n}=133)$ & $52.05 \pm 0.35^{*}$ & $137.18 \pm 0.77^{*, \pi}$ & $31.96 \pm 0.59^{*, @}$ \\
\hline
\end{tabular}

Data are presented as mean \pm SEM. ${ }^{*} p<0.01$ when compared with mean readings of 6 to 8 years (Student's t-test); ${ }^{\prime} p<0.01$ when MMO compared with height (chi-square test); ${ }_{\mathrm{p}}<0.01$ when MMO compared with weight (chi-square test); ${ }_{\mathrm{p}}>0.05$ when MMO compared between boys and girls (Student's t-test) 


\section{DISCUSSION}

The results of the present study revealed that $\mathrm{MMO}$ in Indian children was $41.61,44.9$, and $46.81 \mathrm{~mm}$ for boys and $40.09,44.22$, and $46.2 \mathrm{~mm}$ for girls at ages of 3,4 , and 5 years respectively. Our results are in agreement with the findings reported by Sheppard and Sheppard, ${ }^{4}$ Bernal and Tsamtsouris, ${ }^{7}$ and Gaviao et $\mathrm{al}^{8}$ with $\mathrm{MMO}$ of 42.4, $42 \pm 4.6$, and $45.72 \mathrm{~mm}$ respectively, in primary dentition. Similarly, Rothenberg ${ }^{9}$ recorded a mean of $40.47 \mathrm{~mm}$ for children aged 4 to 6 , and Alamoudi et $\mathrm{al}^{10}$ found $\mathrm{MMO}$ of $41.2 \pm 5.6 \mathrm{~mm}$ for children aged 3 to 7 years, measurements which are closest to this study at age of 3 years. On the contrary, Muhtarogullari et $\mathrm{al}^{11}$ and Cortese et $\mathrm{al}^{12}$ reported lower values of $\mathrm{MMO}$, i.e., 38.2 and $38.59 \mathrm{~mm}$ respectively, in children with primary dentition. In mixed dentition, the MMO in Indian children were $46.04,48.53$, and $52.38 \mathrm{~mm}$ for boys and $45.95,47.27$, and $52.05 \mathrm{~mm}$ for girls at age groups of 6 to 8,8 to 10 , and 10 to 12 years respectively. These values agree well with the values, 46.0 and $46.2 \mathrm{~mm}$, given by Nevakari ${ }^{3}$ and Sheppard and Sheppard, ${ }^{4}$ respectively, for the children aged 6 to 10 years, and the value of $46.4 \mathrm{~mm}$ given by Ingervall ${ }^{5}$ for opening capacity in 7 -year-old children. In contrast, Vanderas ${ }^{13}$ and Ingervall ${ }^{5}$ reported higher values of $\mathrm{MMO}$, i.e., 54.8 and $51.3 \mathrm{~mm}$ respectively, among children between the ages of 6 and 10 years. However, Land twing $^{14}$ reported a mean value of $45.9 \mathrm{~mm}$, regardless of the fact that age range of the children was wider: 5 to 19 years. The difference in MMO values reported by these workers could be due to different methodology used.

The MMO has been reported either as the interincisal distance $e^{1,5,6}$ or as the interincisal distance plus the overbite. ${ }^{8}$ Mezitis et $a l^{15}$ pointed out that the functional opening of the mouth is more important, because this is the value that actually affects chewing and dental treatment. Therefore, the interincisal distance was used as a measurement of MMO in the present study. Wood and Branco $^{16}$ compared direct and extraoral measurements, and suggested that direct measurements using ruler or Vernier caliper were more precise and accurate. While dealing with horizontal movements in the primary dentition, few data ${ }^{17}$ are available in the literature. In the present study, horizontal mandibular movements were not recorded, as it was difficult to get small children to perform these movements. In contrast, Bonjardim et $\mathrm{al}^{17}$ trained 99 Brazilian children aged 3 to 5 years before measuring $\mathrm{MMO}$, but it was not feasible to train every child before measuring $\mathrm{MMO}$ when the study consists of comparable larger sample size as in the present case.

The position of the head during the measurement of MMO is an important factor. ${ }^{18,19}$ Higbie et $\mathrm{al}^{20}$ described how MMO decreases in the order of forward, natural, and retracted head positions. In our study, MMO was measured while the subject rested their heads against a firm wall surface in an upright position in order to eliminate the possible influence of different head positions.

The literature supports that MMO steadily increases after birth until adolescent ${ }^{5,13,15}$ and then gradually decreases as aging progresses. Present study reported a gradual increase in $\mathrm{MMO}$ with age, that is, from 3 to 5 years in primary dentition group and from 6 to 12 years in mixed dentition group. Findings were in agreement with Hirsch et al, ${ }^{21}$ Cortese et al, ${ }^{12}$ and Vanderas ${ }^{13}$ where MMO was found to be directly correlated with age. Abou-Atme et $\mathrm{al}^{22}$ reported moderate to strong correlation between MMO and age in 102 Lebanon children aged 4 to 15 years. Rothenberg ${ }^{9}$ noted significant relationship of maximum vertical opening of mouth with age in 189 Caucasian children, aged 4 to 14 years. Sousa et $\mathrm{al}^{23}$ reported a weak significant correlation between mandibular range of movement and age in 303 Brazilian children aged 6 to 14 years.

Few studies reported gender difference in $\mathrm{MMO}$ in children. ${ }^{7,8}$ In the present study, statistically significant difference was not observed between boys and girls at various age groups. However, $\mathrm{MMO}$ was found to be significantly different when compared between contrast age groups. These findings were similar to the ones reported by many authors ${ }^{14,20,21}$ in children with primary dentition as well as mixed dentition. Abou-Atme et $\mathrm{al}^{22}$ reported no gender difference for measurement of MMO in 102 children aged 4 to 15 years. In contrast, Ogura et al ${ }^{24}$ and Gazit et $\mathrm{al}^{25}$ reported a $5 \mathrm{~mm}$ difference in vertical mandibular opening between young men and women. Similar findings were noted by other authors ${ }^{8,15}$ also. The possible reason for the positive correlation between $\mathrm{MMO}$ and gender for such studies is that low number of children included in each age category might have reduced the significance of the result.

The correlation between MMO and stature and body weight is controversial. Some studies described a positive relationship, ${ }^{26,27}$ while others did not. ${ }^{15}$ Westling and Helkimo $^{28}$ mentioned that $\mathrm{MMO}$ is relatively dependent on the size of the mandible, which is obviously greater in males. Since human males are generally taller and larger than females, it is conceivable that MMO would be larger in males. In addition, Dijkstra et $\mathrm{al}^{29}$ pointed out that differences in MMO may be attributed to the mandibular length. The results of the study revealed a definitive correlation between $\mathrm{MMO}$ with height and weight. Rothenberg ${ }^{9}$ also observed a positive correlation between MMO values in relation to weight and height in subjects with ages between 4 and 14 years. Similar results were obtained by Landtwing, ${ }^{14}$ Sousa et al, ${ }^{23}$ Henrikson et $\mathrm{al}^{30}{ }^{30}$ and Ingervall. ${ }^{5}$ Agerberg, ${ }^{6}$ however, found the weak correlation of MMO to height and weight in all age groups. 
The present study observed that gradual increase in MMO with increasing age, height, and body weight may be due to changes in temporomandibular joint apparatus, facial morphology, muscle development, growth of cranial base and mandible particularly in length. At present, it is difficult to propose the exact mechanism responsible for this increase in MMO. However, this study uses a modified Vernier caliper method for the first time to measure MMO in young Indian children and suggest a positive relationship between $\mathrm{MMO}$, age, height, and body weight.

Assessment of mouth opening is an important part of the clinical examination for clinicians or physicians involved in the treatment of head and neck disorders. In order to diagnose an abnormality, knowledge of the normal condition is essential. The study in combination with clinical expertise serves as an available approach for clinical decision-making to diagnose severe divergences and diseases related to function of the masticatory system.

\section{REFERENCES}

1. Miller VJ, Bookhan V, Brummer D, Singh JC. A mouth opening index for patients with temporomandibular disorders. J Oral Rehabil 1999 Jun;26(6):534-537.

2. Dworkin SF, LeResche L, DeRouen T, Von Korff M. Assessing clinical signs of temporomandibular disorders: reliability of clinical examiners. J Prosthet Dent 1990 May;63(5):574-579.

3. Nevakari K. "Elapsio praearticularis" of the temporomandibular joint. A pantomographic study of the so-called physiological subluxation. Acta Odontol Scand 1960;18(2):123-170.

4. Sheppard IM, Sheppard SM. Maximal incisal opening: a diagnostic index? J Dent Med 1965 Jan;20:13-15.

5. Ingervall B. Range of movement of mandible in children. Scand J Dent Res 1970 Aug;78(4):311-322.

6. Agerberg G. Maximal mandibular movements in young men and women. Sven Tandlak Tidskr 1974 Mar;67(2):81-100.

7. Bernal M, Tsamtsouris A. Signs and symptoms of temporomandibular dysfunction in 3 to 5 year old children. J Pedod 1986 Winter;10(2):127-140.

8. Gaviao MBD, Chelotti A, Silva FA. Análise funcional da oclusão decídua: avaliação dos movimentos mandibulares. Rev Odontol Univ São Paulo 1997;11(1):61-69.

9. Rothenberg L. An analysis of maximum mandibular movements, craniofacial relationship and temporomandibular joint wariness in children. Angle Orthod 1991;61(2):103-112.

10. Alamoudi N, Farsi N, Salako NO, Feteih R. Temporomandibular disorders among school children. J Clin Pediat Dent 1998 Summer;22(4):323-329.

11. Muhtarogullari M, Demirel F, Saygili G. Temporomandibular disorders in Turkish children with mixed and primary dentition: prevalence of signs and symptoms. Turk J Pediatr 2004 Apr-Jun;46(2):159-163.

12. Cortese SG, Oliver LM, Biondi AM. Determination of range of mandibular movements in children without temporomandibular disorders. J Craniomandib Pract 2007 Jul;25(3):200-205.

13. Vanderas AP. Mandibular movements and their relationship to age and body height in children with or without clinical signs of craniomandibular dysfunction: Part IV. A comparative study. ASDC J Dent Child 1992 Sep-Oct;59(5):338-341.
14. Landtwing K. Evaluation of the normal range of vertical mandibular opening in children and adolescents with special reference to age and stature. J Maxillofac Surg 1978 Aug;6(3):157-162.

15. Mezitis M, Rallis G, Zachariades N. The normal range of mouth opening. J Oral Maxillofac Surg 1989 Oct;47(10): 1028-1029.

16. Wood GD, Branco JA. A comparison of three methods of measuring maximal opening of the mouth. J Oral Surg 1979 Mar;37(3):175-177.

17. Bonjardim LR, Gavião MB, Pereira LJ, Castelo PM. Mandibular movements in children with and without signs and symptoms of temporomandibular disorders. J Appl Oral Sci 2004 Mar;12(1):39-44.

18. Eriksson PO, Haggman-Henrikson B, Nordh E, Zafar H. Coordinated mandibular and head-neck movements during rhythmic jaw activities in man. J Dent Res 2000 Jun;79(6): 1378-1384.

19. Visscher CM, Huddleston-Slater JJ, Lobbezoo F, Naeije M. Kinematics of the human mandible for different head postures. J Oral Rehabil 2000 Apr;27(4):299-305.

20. Higbie EJ, Seidel-Cobb D, Taylor LF, Cummings GS. Effect of head position on vertical mandibular opening. J Orthop Sports Phys Ther 1999 Feb;29(2):127-130.

21. Hirsch C, John MT, Lautenschlager C, List T. Mandibular jaw movement capacity in 10-17-yr-old children and adolescents: normative values and the influence of gender, age, and temporomandibular disorders. Eur J Oral Sci 2006 Dec;114(6): 465-470.

22. Abou-Atme YS, Chedid N, Melis M, Zawawi KH. Clinical measurement of normal maximal mouth opening in children. Cranio 2008 Jul;26(3):191-196.

23. Sousa LM, Nagamine LM, Chaves TC, Grossi DB, Regalo SC, Oliveira AS. Evaluation of mandibular range of motion in Brazilian children and its correlation to age, height, weight, and gender. Braz Oral Res 2008 Jan-Mar;22(1):61-66.

24. Ogura T, Morinushi T, Ohno H, Sumi K, Hatada K. An epidemiological study of TMJ dysfunction syndrome in adolescents. J Pedod 1985 Fall;10(1):22-35.

25. Gazit E, Lieberman M, Eini R, Hirsch N, Serfaty V, Fuchs C, Lilos P. Prevalence of mandibular dysfunction in 10-18 year old Israeli school children. J Oral Rehabil 1984 Jul;11(4): 307-317.

26. Reicheneder C, Kardari Z, Proff P, Fanghaenel J, Faltermeier A, Römer P. Correlation of condylar kinematics in children with gender, facial type and weight. Ann Anat 2013 May;195(3): 243-247.

27. Zawawi KH, Al-Badawi EA, Lobo SL, Melis M, Mehta NR. An index for the measurement of normal maximum mouth opening. J Can Dent Assoc 2003 Dec;69(11):737-741.

28. Westling L, Helkimo E. Maximum jaw opening capacity in adolescents in relation to general joint mobility. J Oral Rehabil 1992 Sep;19(5):485-494.

29. Dijkstra PU, de Bont LG, Stegenga B, Boering G. Angle of mouth opening measurement: reliability of a technique for temporomandibular joint mobility assessment. J Oral Rehabil 1995 Apr;22(4):263-268.

30. Henrikson T, Nilner M, Kurol J. Signs of temporomandibular disorders in girls receiving orthodontic treatment. A prospective and longitudinal comparison with untreated Class II malocclusions and normal occlusion subjects. Eur J Orthod 2000 Jun;22(3):271-281. 